NBER WORKING PAPER SERIES

MINIMUM HOURS CONSTRAINTS, JOB REQUIREMENTS AND RETIREMENT

\author{
Alan L. Gustman \\ Thomas L. Steinmeier \\ Working Paper 10876 \\ http://www.nber.org/papers/w10876 \\ NATIONAL BUREAU OF ECONOMIC RESEARCH \\ 1050 Massachusetts Avenue \\ Cambridge, MA 02138 \\ October 2004
}

This paper was supported by a grant from the U.S. Social Security Administration (SSA) to the Michigan Retirement Research Center, UM 03-03, with a subcontract to the National Bureau of Economic Research. The opinions and conclusions are solely those of the authors and should not be construed as representing the opinions or policy of SSA, the Michigan Retirement Research Center, or the National Bureau of Economic Research. Alan L. Gustman is Loren Berry Professor of Economics at Dartmouth College, Department of Economics, Hanover, N.H. 03755 (alan.1.gustman@ dartmouth.edu). Thomas L. Steinmeier is Professor of Economics, Texas Tech University, Department of Economics, Lubbock, Texas 79409 (Thomas.Steinmeier@TTU.edu). The views expressed herein are those of the author(s) and not necessarily those of the National Bureau of Economic Research.

(C) 2004 by Alan L. Gustman and Thomas L. Steinmeier. All rights reserved. Short sections of text, not to exceed two paragraphs, may be quoted without explicit permission provided that full credit, including (C) notice, is given to the source. 
Minimum Hours Constraints, Job Requirements and Retirement

Alan L. Gustman and Thomas L. Steinmeier

NBER Working Paper No. 10876

October 2004

JEL No. H55, J26, J14, J32, E21, D31, D91

\begin{abstract}
A structural retirement model estimated with data from the Health and Retirement Study is used to simulate the effects of policies firms might adopt to improve employment conditions for older workers and thereby encourage delayed retirement. Firm policies that effectively abolished minimum hours constraints would strongly increase the number partially retired, while reducing full time work and full retirement, resulting in only a small net increase in full-time equivalent employment. Reducing physical and mental requirements of jobs would have much weaker effects on retirement than was suggested by work with the 1970s Retirement History Study. Reducing informal pressures to retire, increasing employer accommodations to health problems, and reducing the prevalence of layoffs and retirement windows would have only small effects on retirement outcomes.
\end{abstract}

\author{
Alan L. Gustman \\ Department of Economics \\ Dartmouth College \\ Hanover, NH 03755 \\ and NBER \\ alan.1.gustman@dartmouth.edu \\ Thomas L. Steinmeier \\ Department of Economics \\ Texas Tech University \\ Lubbock, TX 79409 \\ thomas.steinmeier@ttu.edu
}




\title{
Minimum Hours Constraints, Job Requirements and Retirement
}

\author{
By Alan L. Gustman and Thomas L. Steinmeier
}

\section{Introduction.}

As the baby boomers retire and the demand for older workers increases, firms are likely to adopt policies that change employment conditions and constraints in an effort to encourage workers to postpone their retirements. ${ }^{1}$ The goal of this paper is to help us understand how effective such policies would be in influencing workers' retirement decisions. Characteristics of jobs we consider include minimum hours constraints, informal pressures on the job to retire, layoffs, window plans, physical and mental requirements of the job, and accommodations made by the employer when a person has a health problem.

The first step in the analysis is to add indicators of employment constraints and conditions to a structural model of retirement and saving, and thereby determine their effects on retirement behavior. Second, we simulate the effects of changing the influence of a number of firm side employment policies on retirement outcomes. We do not consider here the extent to which firms would be willing to relax these constraints. Rather, we examine supply side responses to changes in employment conditions, i.e., how individuals would change their behavior were employment constraints no longer binding, or other job conditions modified.

Section II briefly discusses hours constraints and job characteristics that may affect retirement outcomes. The retirement model is presented in Section III. Section IV describes the

${ }^{1}$ As the baby boomers come even closer to retiring, other things the same, relative wages paid to older workers are likely to increase, pension plan features that encourage early retirement will continue to disappear, and nonwage characteristics of jobs will evolve to encourage delaying retirement. These changes will continue to mitigate, or perhaps even reverse, what was a strong trend to earlier retirement that, after many years, began to level out in the mid 1980s (Costa, 1998, 1999; Quinn, 2002). 
data and Section V the basic estimates of the parameters of the structural model. Section VI examines the role of job conditions in the preference function. Simulations of the effects of relaxing a number of constraints and job conditions are presented in Section VII. Section VIII concludes.

\section{Job Characteristics in Retirement Analysis.}

In this section we discuss several characteristics of the job that may affect when an individual decides to retire.

\section{Minimum hours constraints.}

A minimum hours constraint is a limitation imposed by the firm requiring a minimum number of hours of work for a specified job. It has been known for some time that most jobs do not permit a person to retire gradually by reducing hours of work. ${ }^{2}$ The choice facing most workers on their long term jobs is to work full time or not at all. Theory tells us that in the absence of any constraints (minimum hours constraints or a fixed cost of work), most people would prefer to gradually reduce their time at work as they age. Moreover, given the higher wage paid on jobs held for a long time, they would prefer to partially retire on their long term jobs. As a result of the minimum hours constraints imposed by their employers, however, they are not free to do so. ${ }^{3}$ Consequently, the predominant retirement path is from full time work to complete retirement, with a significant fraction, but still a minority, passing through partial

${ }^{2}$ Gustman and Steinmeier $(1983,1984 b)$ document the existence of minimum hours constraints facing retirement age workers. In a recent paper, Even and Macpherson (2004) use HRS data to discuss the relation between coverage by pension plans of different types and minimum hours constraints.

${ }^{3}$ Gustman and Steinemeier (1983) and Hurd (1996) list a number of reasons why firms choose to adopt minimum hours constraints, including fixed costs of employment, team production and other factors. 
retirement (Gustman and Steinmeier, 1984a, 2000). ${ }^{4}$ Should tighter labor markets encourage firms to relax their minimum hours constraints, the frequency of partial retirement will increase, while both full retirement and full time work will become less common.

Informal pressures to retire.

These pressures, which may come both from employers and from co-workers and are aimed at older workers, may encourage older individuals to leave the firm. By affecting job satisfaction, these pressures may encourage earlier leaving even if the wage offer is not lowered. Layoffs.

There is ample evidence that experiencing a layoff at older ages affects retirement outcomes. In the Retirement History Study, involuntary termination came not just from layoffs, but from mandatory retirements, which affected most of the population reaching age $65 .^{5}$ Chan and Stevens (2001) use data from the Health and Retirement Study to explore the reduction in employment prospects for those who experience a layoff. However, our major focus here is not on retirement experience conditional on having experienced a layoff. Rather it is on the overall effect of abolishing layoffs on retirement outcomes.

Early retirement windows.

${ }^{4}$ Gustman and Steinmeier (1986a) demonstrate the importance of including minimum hours constraints in structural retirement models. When these constraints are the reason most workers proceed directly from full time work to complete retirement, but a model assumes workers are free to work part time on their main job but choose not to, the resulting estimates will suggest that work and leisure are very close substitutes. Thus the model will generate corner solutions, with most individuals moving immediately from the corner with full time work to the corner with full retirement. Once it is recognized that minimum hours constraints prohibit most older workers from phasing smoothly into retirement, preference estimates will show that in the absence of these constraints, most people would prefer to reduce their time at work smoothly as they phase into retirement, but their firms' policies prevent them from doing so.

${ }^{5}$ Gustman and Steinmeier (1986a) examined the effects on retirement of mandatory retirement as well as layoffs using data from the Retirement History Study. 
Similarly, early retirement windows offer one time or periodic changes in retirement rules that may encourage complete retirement by those who receive the offer (Brown, 2000, 2002, 2003). ${ }^{6}$ These rule changes may enhance the value of the pension by crediting more years of work, by relaxing the early retirement age, by providing retiree health insurance, or by enhancing the reward to earlier retirement in other ways. Windows may also carry an implicit threat that if the worker does not sign up for the window plan, layoffs may follow. As in the case of layoffs, our interest here is in the effect of eliminating window plans on overall retirement outcomes for the population, rather than on the effect of a window plan on those who were offered the plan.

Physical difficulty and mental stress.

Data collected in the 1970s by the Retirement History Study (RHS) suggest that employment conditions also influence retirement. For example, Gustman and Steinmeier (1986b) find that workers in blue collar jobs prefer to retire earlier than those in white collar jobs. Although those in the Health and Retirement Study (HRS) cohort - those born from 1931 to 1941 in the HRS sample -- disproportionately hold union and manufacturing jobs when compared to those in younger cohorts (Gustman, Mitchell and Steinmeier, 1995), physically demanding jobs are less common for those verging on retirement today than they were in the past. Both the physical difficulty of work and the other challenges employment presents to older

${ }^{6}$ Brown (2002) finds that in the early 1990s, there were roughly five offers of windows plans per hundred workers, and roughly a third of those offered a plan accepted. Those offered a window plan were closer to early retirement age and thus were expecting to retire sooner than others. Brown (2003) confines his study of those who are offered and accept a window plan in the HRS to workers who were covered by a defined benefit plan. He finds that roughly $600 \mathrm{HRS}$ respondents from the original cohort eventually accepted the offer of a window plan. About 200 respondents had already accepted such an offer before the first wave of the HRS, and half of those had returned to work in the first wave, presumably for a different employer. Between subsequent waves, roughly a third of those who accept a window plan are employed in the next wave. 
workers are measured in the HRS. Below we quantify the effects of difficultly of work and related conditions of employment on the decision to retire in today's job market.

\section{Employer accommodations.}

As increasing age and declining health make it more difficult to meet the physical demands of work, some employers may accommodate older workers by allowing changes in job tasks, while others may make no accommodation. Moreover, certain jobs are by their nature more accommodating to aging workers, allowing greater autonomy, providing flexibility, and in other ways promoting a work environment that is more favorable to older individuals. An extreme form of accommodation to older workers is flexibility of hours. Job reassignment may also help to prolong the productive work life of an older employee. Conditional on the physical and mental demands of jobs, we will ask how accommodation is associated with retirement outcomes. Of course, if accommodations are provided on jobs where workers are most likely to retire for unobserved reasons, then this type of evaluation of the effects of accommodating older workers will be biased.

Many studies have considered the effects of one or another of these firm side employment conditions when analyzing retirement behavior. Hurd (1996) provides an excellent summary. Some of these constraints have been examined in reduced form studies. ${ }^{7}$ Our contribution is to consider their effects in the context of a structural model of retirement and saving for the period of the 1990s.

${ }^{7}$ Haider and Loughran (2001) find that the proportion of older workers who report their job requires lifting heavy loads, stooping, kneeling or crouching, and good eyesight declines with age between 50 and 79 . These findings are consistent with earlier findings that certain characteristics of the job interact with age, as some jobs become more difficult to perform at older ages than others. 


\section{The Basic Retirement Model.}

Our analysis is built around a structural model of retirement and saving that we have introduced in previous work. We have used the model for policy analysis, in one case simulating the effects of raising the Social Security early entitlement age (Gustman and Steinmeier, 2004) and in another, simulating certain proposals made by the President's Commission to Strengthen Social Security (Gustman and Steinmeier, 2002). A full description of the methodology in estimating the model and using it to simulate policy is found in our earlier work.

\section{Utility.}

In the model, the individual is assumed to maximize a utility function of consumption and leisure over time:

$$
\mathrm{U}=\sum_{\mathrm{t}=0}^{\mathrm{T}}\left\{\mathrm{e}^{-\rho \mathrm{t}} \sum_{\mathrm{m}=1}^{3}\left[\mathrm{~s}_{\mathrm{m}, \mathrm{t}}\left(\frac{1}{\alpha} \mathrm{C}_{\mathrm{m}, \mathrm{t}}^{\alpha}+\mathrm{e}^{\mathrm{x}_{\mathrm{t}} \beta+\varepsilon} \frac{1}{\gamma}\left(\mathrm{L}_{\mathrm{m}, \mathrm{t}}^{\gamma}-1\right)\right)\right]\right\} \quad \alpha, \gamma<1
$$

In this equation, $\mathrm{T}$ is the maximum lifespan and $\mathrm{m}$ refers to the family structure at time $\mathrm{t}$ (both spouses alive, only the husband alive, or only the wife alive). $s_{\mathrm{m}, \mathrm{t}}$ is the probability of family structure $\mathrm{m}$ at time $\mathrm{t}, \mathrm{C}$ is consumption, and $\mathrm{L}$ is the leisure, which takes on a value of 0 for full-time work, 1 for full retirement, and $1 / 2$ for partial retirement. ${ }^{8} \quad \mathrm{X}$ includes a constant, age, health status, and vintage. The age variable in $\mathrm{X}$ causes leisure to become gradually more attractive as the individual ages, reflecting the gradual wear and tear which makes the rigors of work relatively less attractive. As the value of leisure increases for this reason and perhaps also because of worsening health, at some point the utility of leisure

\footnotetext{
${ }^{8}$ In recognition that consumption is more valuable while both spouses are alive, the consumption function is adjusted so that the marginal utility for a surviving spouse is approximately equal to that for a couple consuming $40 \%$ more.
} 
surpasses the utility of the consumption that continued work makes possible, and the individual retires. It is important to note explicitly that $\mathrm{X}$ does not contain any binary age variables or splines in age which might encourage retirement at a particular age.

For this study, $\mathrm{X}$ also contains several variables associated with nature of the job. These variables include measures of the difficulty and stress of the job, the degree to which the respondent feels age discrimination in the job, and whether or not the employer will accommodate a worker who has health problems. These variables are an important part of the means by which job requirements and conditions influence retirement.

\section{Heterogeneous Elements of Utility.}

The preferences allow for three types of heterogeneity. The time preference term $\rho$ is a fixed effect, and the leisure preference term $\varepsilon$ is a random effect drawn from a normal distribution. The parameter $\gamma$, which governs how desirable partial retirement is relative to full retirement or full-time work, is also a random effect. It is taken so that the term $(1 / 2)^{\gamma}$ comes from the exponential distribution $\mathrm{f}\left[(1 / 2)^{\gamma}\right]=\mathrm{ke}^{\delta(1 / 2)^{\gamma}}$ defined over $(1 / 2)^{\gamma} \in[1 / 2,1]$, which is the theoretically acceptable range of $(1 / 2)^{\gamma}$ for $\gamma \in[0,1]$. $\mathrm{k}$ is the constant necessary for the density function to integrate to unity, as it must. Since partial retirement seems to become relatively more attractive as the individuals age, we specify $\delta$ to be increasing in age: $\delta=\delta_{\mathrm{o}}+$ $\delta_{\mathrm{a}} \times$ Age

\section{The Budget Constraint.}

The asset accumulation over time is given by

$$
A_{m, t}=(1+r) A_{k, t-1}+W_{m, t}\left(1-L_{m, t}\right)+E_{m, t}+B_{m, t}-C_{m, t}, \quad \text { with } A_{m, t} \geq 0
$$

where $A_{m, t}$ is the level of real assets at time $t$ in survival state $m, r$ is the real interest rate, 
$\mathrm{W}_{\mathrm{m}, \mathrm{t}}$ is the real wage rate, $\mathrm{E}_{\mathrm{m}, \mathrm{t}}$ is the earnings of the spouse, and $\mathrm{B}_{\mathrm{m}, \mathrm{t}}$ is the level of Social Security and/or pension benefits at time t. The equation must hold for any legitimate transition between survival state $\mathrm{k}$ at time $\mathrm{t}-1$ and survival state $\mathrm{m}$ at time $\mathrm{t}$. If the individual is working, the wage rate may depend on whether the work is full-time or part-time. The earnings and pension benefits of the spouse are treated as exogenous in this paper.

The level of benefits $B_{m, t}$ at time $t$ depends on the previous decisions of the individual as to when to leave full-time employment and when to retire fully, as well as the current survival state. Note that this model does not calculate the value of accruals to Social Security and pensions directly, but the value of the accruals is implicit in the model because work during one period will affect the value of Social Security and pension benefits in later periods. The implicit value of these accruals, of course, depends strongly on the time preference rate.

\section{Job Characteristics in the Utility Function.}

The main difference between this model and the models we have estimated before is that this model contains indicators of job-specific explanatory variables in the X $\beta$ linear form. ${ }^{9}$ In previous work, we wrote the leisure term (excluding the $\varepsilon$ and $\frac{1}{\gamma}$ terms) as $e^{x_{t} \beta} L^{\gamma}$. However, now $\mathrm{X}_{\mathrm{t}}$ takes on different values depending on whether we are talking about full-time jobs or partial retirement jobs. This requires some modification of the leisure part of the utility term. To see why, let $\mathrm{X}$ be $\mathrm{X}_{\mathrm{ft}}$ and $\mathrm{X}_{\mathrm{pt}}$, depending on whether the job is full-time or partial retirement. Recall that $\mathrm{L}$ takes on a value of 0 for full-time work, $1 / 2$ for partial retirement, and 1 for full retirement. In this case, the values of the term $\mathrm{e}^{\mathrm{x}_{\mathrm{t}} \beta} \mathrm{L}^{\gamma}$ for the various work/retirement states are:

${ }^{9}$ Another difference is that the respondent contributes something to the moment matrices at more ages than in our previous work because we impute the retirement status between the survey dates. In previous work, we used the retirement status just at the survey dates. 
Full-time work: $\quad 0$, since $\mathrm{L}=0$ for full-time work

Partial retirement $\quad e^{X_{p t} \beta}(1 / 2)^{\gamma} \quad$, since $L=1 / 2$ for part time work

Full retirement $\quad \mathrm{e}^{\mathrm{X}_{\mathrm{tit}} \beta} \quad$, since $\mathrm{L}=1$ for full retirement.

The problem with this formulation is that the utility difference in going from partial

retirement to full retirement is $\mathrm{e}^{\mathrm{X}_{\mathrm{tt}} \beta}-\mathrm{e}^{\mathrm{X}_{\mathrm{pt}} \beta}(1 / 2)^{\gamma}$, and this difference depends on the characteristics of the full-time job, which it should not. The solution is to realize that the term $\mathrm{e}^{\mathrm{x}_{\mathrm{t}} \beta} \mathrm{L}^{\gamma}$ measures the utility of leisure relative to full-time work, but what we really want to do is to measure it relative to full retirement. Thus, ignoring for the moment the exponential terms, the utility of the three retirement states $\mathrm{L}^{\gamma}$ is as follows:

Full retirement $\quad 1^{\gamma}=1$

Partial retirement $\quad(1 / 2)^{\gamma}$

Full-time work $\quad 0^{\gamma}=0$

Relative to utility at full-time retirement, these are

Full retirement $\quad 1-1=0$

Partial retirement $\quad(1 / 2)^{\gamma}-1$

Full-time work $\quad 0-1=-1$

We then add the exponentials terms:

Full retirement $\quad 0$

Partial retirement $\quad \mathrm{e}^{\mathrm{X}_{\mathrm{p} \beta} \beta}\left[(1 / 2)^{\gamma}-1\right]$

Full-time work $\quad-\mathrm{e}^{\mathrm{x}_{\mathrm{n}} \beta}$

In this formulation, the job characteristics apply only to those utility differences between the job in question and full retirement. A change in the characteristics of the partial retirement job will affect the utility of that job relative to both full-time work and full retirement, but will not affect the utility of full-time retirement relative to full-time work. Similarly, a change in the characteristics of the full-time job will change the utility of the leisure (or lack thereof) in that 
job relative to partial retirement work and full retirement, but will not change the valuation of partial retirement leisure relative to full retirement.

Thus, the utility of leisure term in the utility function, including $\varepsilon$ and $\frac{1}{\gamma}$, should be:

$$
\mathrm{e}^{\mathrm{X}_{\mathrm{j}} \beta+\varepsilon} \frac{1}{\gamma}\left(\mathrm{L}_{\mathrm{j}}^{\gamma}-1\right)
$$

where $\mathrm{j}=\mathrm{w}, \mathrm{p}$, or $\mathrm{r}$ (working full-time, partially retired, or fully retired). Note that $\mathrm{X}_{\mathrm{jt}}$ does not have a defined value for $\mathrm{j}=\mathrm{r}$, but that does not matter since for $\mathrm{j}=\mathrm{r}, \mathrm{L}_{\mathrm{j}}^{\gamma}-1$ is equal to zero.

Since the job characteristics in the partial retirement job are not observed for most individuals, we assume that the characteristics (difficulty, stress, and age discrimination) are no greater than the median of the characteristics or the value in the full-time job, whichever is less.

\section{The Data.}

Estimates in this paper are based on a sample of long term married men from the first six waves of The Health and Retirement Study (HRS). The survey is taken every two years, so the data cover the period 1992 through 2002. In 1992 the HRS sample consisted of 12,652 persons from households with a respondent who was 51 to 61 years old. The study also uses restricted, linked employer provided pension plan descriptions and Social Security earnings records matched with respondents in 1992.

Table 1 describes the derivation of the sample from the HRS. Table 2 reports the distribution for the observed retirements in the sample. The dependent retirement variable is based on hours of work and is described in Appendix 1. The percentages retired from full-time work and completely retired are calculated as percentages among those respondents who had retirement status observations at each particular age. The columns "retiring in year" are really 
pseudo-retirements, calculated as the difference between the percent retired at a particular age and the percent retired at the immediately preceding age. From Table 2, the spike in retirements at age 62 is readily apparent. The spike in retirements from full time work at age 65 is much smaller.

The first explanatory variable of interest reflects whether the respondent reports being permitted to partially retire on the job held in the first wave. If the answer is yes, it is assumed that the wage rate remains unchanged if the respondent partially retires. Otherwise, there is a reduction in the wage associated both with partially retiring and with the loss of job tenure.

Construction of other key variables is reported in Appendix 1. There we describe the construction of two sets of independent variables, one reflecting physical difficulty of the job, the other job stress. The measure of physical stress is constructed from answers given to questions about physical effort, lifting heavy loads and requirements for stooping, kneeling or crouching. Mental stress is measured from variables indicating whether the job requires intense concentration or attention, more difficult things than required of the respondent than in the past, and whether the job involves a lot of stress. These indices run from 0 to 9 , with 9 indicating strong agreement with the questions indicating stress.

The next measure described in Appendix 1 is related to age discrimination. It is constructed from the answers to questions about whether the employer gives preference to younger persons in promotion decisions; and whether co-workers make older workers feel they should retire before 65 . The constructed variable varies from 0 to 6 , with 6 indicating the most age discrimination. 
The three variables enter linearly into the linear form of the exponential expression which multiplies the utility function. The medians of the three variables respectively are 3 (job difficulty), 6 (job stress) and 2 (age discrimination).

A fourth measure that enters into the utility function indicates, for a respondent who reported a condition limiting the amount of work that could be performed, that the respondent's employer had made no accommodation so that the respondent could continue working. These questions are only asked of those who indicated a health problem. If the respondent had a health problem and if the response to the accommodation question is no or if the respondent left the job immediately, the "no accommodation" variable is set equal to 1. Otherwise it is zero.

Two other variables pertain to the budget constraint. First, if the 1992 job ended in a layoff, the wage for a new full time job is calculated assuming zero tenure. Second, if a person accepts a window offer, the wage for full time work is assumed to be the wage paid on a new job with zero tenure.

\section{Empirical Estimation.}

Estimation is based on the general method of simulated moments. The simulated moments come from solutions to the model based on 10,000 random draws of the random effects. Once the model is estimated, including the various retirement outcomes, the model is used to examine the effects of various Social Security parameters. Since we have estimates of the preferences of the individuals, the simulations involve changing the Social Security parameters and running the model. The simulations are performed the same way the simulations are for the moments, by solving the model 10,000 times for random draws of the random effects. 
Table 3 reports the results for the parameters of the utility function where each of the new measures is included. The age, health, consumption coefficient and standard deviation of leisure preference are all significant and of similar orders of magnitude as in our earlier work. As we found earlier, time preference is bimodally distributed.

Table 4 uses the model to simulate retirement outcomes. The model fits the data well. ${ }^{10}$ Moreover, as in our recent work, the model is capable of simulating most of the spike in retirements at age 62 , despite the fact that there are no age dummy variables included in the model, and that the Social Security benefit formula is actuarially fair around age 62. To be more specific, although the model understates the number retiring at ages 62 and 65, the model comes close to simulating the true distribution of retirements. According to the simulations, 7.2 percent more of the population leaves full time work at age 62 rather than 61 . In comparison, in the raw data, 8.8 percent more of the population leaves fulltime work at 62 rather than 61 . So the simulations catch most of the retirement spike at age 62. The model also catches an age 62 peak

${ }_{10}$ There are 46 moments that are the same as those included in our earlier paper (Gustman and Steinmeier, 2004). In addition, there are 5 more each for high job difficulty (4-9), high job stress (7-9), high age discrimination (3-6), and lack of accommodation to health problems at ages 55, $58,60,62$, and 65 . The moments of the first three job-related variables are measured in the last observed full-time job, since this is job that is most relevant to retirement. The fourth variable is measured in the original (1992) job. This makes for 66 moments. Subtracting off the number of parameters, the model has 54 degrees of freedom for the $\mathrm{q}$ statistic. The cut-off point for the chisquare distribution at $1 \%$ is 80.3 for 54 degrees of freedom. The model's computed q-statistics are outside these bounds, but not by a large amount.

The 46 moments from the basic model are as follows: Thirteen moments are for the percentages working full-time at each age between 54 and 66. Additional moments taken at ages $55,58,60,62$ and 65 are for the percentage fully retired, the percent of those with a health problem who are working full-time, the percent of those with a health problem who are fully retired, the percent of those born before 1934 who are working full-time, the percent of those born after 1938 who are working full-time, the percent of those with lifetime incomes below $\$ 1,250,000$ who are working full-time, and the percent of those with lifetime incomes above $\$ 1,900,000$ who are working full-time. In cases in which respondents are not observed at particular ages, the corresponding moments are treated as missing both in the moment vector and in the estimated variance matrix of the moment vector. 
in retirements from both full and part time work out of the labor force. However, there it finds the peak between age 61 to 62 represents 4.6 percent of the labor force, whereas in the raw data, that spike represents 7 percent of the labor force.

\section{Job Characteristics, Preferences and Retirement Outcomes.}

In Table 3, among the newly entered measures, only the measure of age discrimination is statistically significant, and even then at only the $10 \%$ significance level. Measures of difficulty of work, including type of job, have no significant effect on retirement preferences. The presence of job accommodations for those with a health problem also has no effect on the perceived disutility of work.

The lack of significance of the job difficulty and job stress variables is contrary to expectations, given that a measure of blue collar work was significant and important in our earlier work using the RHS. There is considerable variability in the measures of job difficulty or job stress, so a lack of variation in the independent variable is not a problem. ${ }^{11}$

To see whether the negative result for the job difficulty variable is the result of something in the estimation or is reflected in the raw data, we separate the estimation sample into two groups according to the level of the job difficulty variable. The observed retirement percentages for these two groups are as follows: At age 58, the retirement rates are 22.5 percent for high difficulty jobs and 24.5 percent for low difficulty jobs. At age 62, the retirement rates are 54.9 for high physical difficulty jobs vs. 54.7 for low difficulty jobs. Thus, the coefficients are merely

\footnotetext{
${ }^{11}$ The distributions of the job difficulty and job stress variables suggest quite a bit of variation. For the job difficulty variable, the counts in the ten categories (0-9) are 894, 491, 428, 605, 436, $335,317,317,91$, and 351 . For the job stress variable, the counts for the ten categories are 14, $26,125,290,568,897,990,726,726$, and 186 . These counts certainly suggest enough variation that the variables should have caught any effect if it was there.
} 
reflecting the patterns of the underlying data and do not seem to be artifacts of the estimation procedure.

This result is contrary to our previous work using the RHS, which indicated that workers in blue collar jobs retired earlier because the blue collar variable in the utility function was significant. There are three potential explanations of this difference. First, the job difficulty measure used here may not be a good substitute for the blue collar status used in the RHS. Secondly, because the job difficulty measure has to be imputed to anyone already retired in 1992, the imputations may be causing the problem. Third, the nature of work may have changed between the RHS and HRS in such a way that blue collar status does not have the negative effect on retirement that it once had.

To sort through the possibilities, we turn to simple tabulations of the data. We classify workers as blue collar or white collar based in the occupation of the current or last job in $1992 .^{12}$ This variable matches the variable used in the RHS, thereby making the variables in the two surveys comparable. Also, occupation is available for almost everyone in the sample, whether or not they were working in 1992, and hence avoids the problem that the results may be due to imputations.

The top half of Table 5 gives the observed retirement rates by age for married males in the 1992 Wave of the HRS. Retirement in this table is taken to be anyone who is either partially or fully retired. The left columns use the self-reported definition of retirement, which is available for almost everyone in the sample. The right columns use an alternative definition of retirement which applies to anyone who is not working more than 30 hours per week and at least 1560 hours per year. The averages over all the ages are weighted by the number of observations

\footnotetext{
${ }^{12}$ White collar includes managerial, professional, sales, clerical, and administrative support occupations. Blue collar includes all other occupations except armed forces.
} 
at each age and therefore weight the ages before 61 more heavily, since males over age 61 are included in the sample only by virtue of being married to wives in the 51-61 age range. ${ }^{13}$

Both definitions yield similar results. Even in these simple and basic tabs, there does not seem to be a clear tendency for blue collar workers to retire more than white collar workers until after about age 60. After age 61, there is a more pronounced tendency for blue collar workers to be retired more often, resulting in an average retirement rate that is 5-7 percentage points higher for blue collar workers, averaged over the 55-65 age range.

However, for the estimation, individuals are dropped out of the sample once they start collecting Social Security Disability Insurance (SSDI) benefits on the grounds that a disabled individual does not really have the option of continuing work (a justification for this can be found in Bound, 1989). Moreover, disability has a strong correlation with blue collar status. Taking as disabled someone who has applied for and been accepted for Social Security disability benefits before the 1992 survey, 3.3\% of married males who were employed in white collar jobs in their current or last jobs are disabled, while $9.6 \%$ of similarly situated blue collar are disabled.

Even among married males not on disability, blue collar workers appear to have worse health than white collar workers. Here we use question B1, which asks whether the respondent considers his health excellent, very good, good, fair, or poor. We take poor health to be those who answer fair of poor. This question was asked long before the labor force questions were asked in the survey and avoids some of the potential endogeneity of the "does health limit the amount or kind of work you can do?" question. Among workers not on SSDI, 9.7 percent of

\footnotetext{
${ }^{13}$ The low level of retirements by white collar workers at age 64 , compared to 63 and 65 , is most likely a reflection of the small sample sizes in each occupation-age category. After age 62 there are approximately fifty observations at each year of age for white collar and blue collar workers. That is less than half the number of observations in each occupation-age cell at younger ages.
} 
white collar workers reported themselves as being in poor health, while 21.1 percent of blue collar workers did so.

The bottom part of Table 5 reports on the retirement percentages for workers in good health who have never received SSDI. Among this group, there are about as many ages where white collar workers have higher retirement rates than blue collar workers as the other way around, and the weighted average retirement rates of the white collar workers is slightly higher than that of the blue collar workers. Thus, it appears that even in simple tabulations of the data, once health and SSDI status are controlled for, there is little evidence that blue collar workers retire earlier. This is contrary to what we found in the RHS.

Also contrary to expectations is the fairly large and negative coefficient of the variable indicating that the employer failed to accommodate a health problem. Again, we wish to see whether this pattern is present in the sample data. Table 6 presents the retirement rate by age for that part of the estimation sample for which an employer had failed to accommodate a health problem. These results may be compared to Table 2, which presents comparable information for the entire sample. Although Table 6 is based on a fairly small number of observations, it is apparent that for many of the ages the retirement rates for those indicating that no accommodation was made for a health problem is actually lower than for the sample as a whole.

It is difficult to check for this, but one possibility is that the accommodation varied with the severity of the health problem. Suppose that employers tend not to accommodate what they perceive as a minor health problem, and that those employees tend to work almost as long as those without health problems. Then the "health problem" variable measures the effect of a major health problem which is accommodated, and the "no accommodation" variable measures the effect of more minor health problems. Under these circumstances, the effect of the "no 
accommodation" variable is measured relative to the "health variable," since the lack of accommodation implies some kind of health problem. If the "no accommodation" group has milder health problems, its coefficient may be negative relative to the "health problem" group, since the latter involves more serious health problems.

In summary, of the four measures of job conditions introduced into the model, only the measure of age discrimination is of the expected sign and close to significance. Measures of job difficulty, job stress, and whether or not the employer accommodates health problems have low significance levels and are sometimes of the wrong sign. However, an analysis of the underlying data suggests that the lack of significance of these coefficients accurately reflects the patterns in the observed data that there is little correlation between these measures and retirement outcomes.

\section{Alternative Specifications.}

Given that the coefficient of the no accommodation variable is nontrivial in magnitude and of the wrong sign, though insignificant, and that the coefficients of the job difficulty and job stress variables are small and insignificant, it is of interest to ask whether these variables might be influencing the estimates of the remaining coefficients. This issue is investigated in Table 7. The first column of estimates of that table is repeated from Table 3. The next column drops the no accommodation variable, and the last column drops additionally the job difficulty and job stress variables.

The estimates indicate that dropping these variables has almost no influence on the estimates of the remaining variables. In particular, the estimate of the age coefficient in $\beta$, which determines how responsive individuals are to economic incentives, is essentially unchanged in the alternative specifications. Also unchanged are the simulated retirements from these alternative specifications. That is, the figures analogous to Table 4 for the alternative 
specifications are almost the same as the figures in Table 4, and consequently they are not reported separately.

\section{Simulations.}

We use the model to simulate retirement outcomes under alternative conditions. That allows us to determine the magnitudes involved, beginning with minimum hours constraints, proceeding to the effects of each of the employment conditions, and then to the effects of layoffs and window plans. These simulations also provide an idea of the likely effect that employer accommodations of various types might have on retirement, should employers attempt to make employment more attractive to older workers as the baby boomers retire. The first panel of Table 8 presents baseline results. The following panels present results obtained by simulating, while assuming the taste parameter or the constraint of interest is changed as indicated. ${ }^{14}$ Table 9 presents the relevant differences between the result with a changed constraint or taste parameter and the baseline result.

All the simulations use the same time preference rates, and the same draws for the random variables, as are used in the base simulation. Thus, any differences cannot be attributed to differences in the random draws. All simulations are for estimates with job difficulty and job

${ }^{14}$ In fact, for each potential change, we ran three simulations. The first is for the complete sample with the indicated change. The second is for the restricted sample for whom the change applies, but without the change. This is essentially the base simulation on a restricted sample. The final simulation is for the restricted sample, with the change. By comparing the first simulation with the base sample, the result indicates the effect of the change on the entire population. By comparing the last two simulations, the result indicates the effect of the change on the population affected by the change. Those policies that will have only a small effect on the overall population typically also have only a very small effect even on the affected population. Consequently, the full results are reported only for the overall population. We discuss the results for the affected group when the impact on the overall population is large enough to warrant further investigation. 
stress variables, but omitting the no accommodation variable from the utility function. These are the results in column (2) of Table 7.

Six potential changes are analyzed:

No hours limits.

All individuals are assumed to be able to switch to partial retirement in their full-time job with no change in wage rate, so they are paid half the earnings for half the work. This affects all respondents except those in full-time jobs which began prior to age 50 and which would allow half-time work in those jobs. Implicitly, this assumes that respondents could collect their full pensions at the age they change from full time work to part time work. Thus the simulation assumes the policy change deals with two of the major issues limiting part time work: hours constraints are relaxed and in addition, the current law prohibiting paying a pension to a person who continues to work for the firm is eliminated. ${ }^{15}$

A comparison of panel 2 with panel 1 of Table 8 clearly indicates that if demand side changes persuaded firms to allow partial retirement at the same hourly wage as earned on the long term job, this would generate a major change in retirement outcomes. From the last column of Table 8, the percent of the labor force that passed through partial retirement would increase from about three tenths to about two thirds. To make the differences easier to follow, the first panel of Table 9 reports the difference in retirement outcomes between a simulation where there are no constraints on partial retirement and a simulation with the current restrictions on partial

${ }^{15}$ The simulations also eliminate the disincentive to partial retirement by those with DB plans who might find their benefits reduced when part time wages earned at the end of the life cycle are counted when computing the average wage measure used in a final average salary benefit formula. When we abolish the hours constraint and let individuals draw on pensions when they partially retire, the pensions are calculated as though they quit at that point. Earnings and service during the period of partial retirement are not included in the pension calculation. For further discussion of the ERISA rule prohibiting a person from working part time while collecting a pension benefit from a long term employer, see Fields and Hutchens (2002), Even and Macpherson (2004), and Penner, Perun and Steurle (2002). 
retirement. From the first row, when partial retirement is unconstrained, the fraction completely retired declines by 4.7 to 14.1 percentage points at each year of age between 58 and 65 . For ages 67 and 69 , the number who are completely retired falls by 15.3 and 13.8 percentage points respectively. From row three, the percent who are not retired at all also declines. The percentage not retired falls at each age, from a reduction of 7.5 percentage points at age 58 to a reduction of 8 percentage points at age 65 . The reductions in full time work and in complete retirement flow into the ranks of the partially retired.

Comparing the change in the percent completely retired from full time work with the change in the percent partially retired, the effect on total earnings is roughly a wash, or suggests a slight decline. Roughly twice as many people enter partial retirement as leave full time work. Since the simulation suggests twice as many hours worked in a full time job as when partially retired, this change suggests that work lost through acceleration of retiring from full time work is roughly balanced by the fact that twice as many people now work part time. On balance, roughly half the increase in partial retirement comes from full time work, and half comes from full retirement, but the amount coming from full retirement increases with age, while the amount coming from the ranks of the not retired is greatest in the age range from 58 to 65 .

For those 65 to 69 , the opportunity to work part time increases the number partially retired by about 20 percentage points. It reduces the number working full time by $8,5.9$ and 3.1 percentage points at ages 65,67 and 69 respectively. Consequently, for those 65 and above, the increase in part time workers is much greater than twice the decline in full time workers, suggesting a 3 to 5 percentage point increase in full time work equivalents from ages 65 to 69 . In this age range, partial retirement becomes three or four times more common than full-time work, as compared to being roughly equally common in the current environment. 
Age discrimination.

The age discrimination variable is lowered to the median value if it was at a higher level. In addition, if an individual was in a 1992 job with above median age discrimination and subsequently moved to an easier job, the simulation assumes that the respondent could have continued on the original job. Looking at panel 2 in Table 9, computed from panels 3 and 1 in Table 8 , it would appear that abolishing the impact of age discrimination on individual preferences would increase the ranks of the not retired by about one percentage point while reducing the ranks of the partially retired by about half a percentage point. Thus with a reduction in part time work, which we simulate as half time jobs, the addition to full-time equivalent employment would be less than one percent.

No layoffs.

If the respondent was laid off from his 1992 job, the base simulation assumes that subsequent full-time work would be in a new job with zero tenure, whether or not the individual was subsequently observed in full-time work. In this simulation, we assume that he could have continued working in that job rather than switching to a different job at zero tenure. Partial retirement wages are assumed to be unchanged. The results in Tables 8 and 9 suggest that eliminating layoffs would have almost no effect on simulated retirements.

\section{Windows.}

All windows, that is special offers to provide an additional amount or pension benefit to those who retired at a specified time, are eliminated. ${ }^{16}$ In addition, if the individual took a

\footnotetext{
${ }^{16}$ The aspects of windows that are measured are lump sum payments, additional pension benefits, and additional years of service credited toward the pension. If the individual accepts the window, he or she receives the lump sum or the extra pension. These benefits are not available if the individual retires in later years. Offers of additional health insurance coverage in retirement are not measured, partly because they are difficult to value and partly because they are not too important. Of those who answered the early-out windows section of the 1992 survey, 327 listed
} 
window offer in the 1992 job, it is assumed in the base simulation that subsequent full-time work would have been in a new job with tenure reset to zero. In this simulation, it is assumed that the individual could have continued in the job that offered the window.

The effect of eliminating windows is to increase the percent at full time work by about half of a percentage point for those 58,60 and 62. It has no effect at other ages. Most of the effect comes from reducing the number who are completely retired. The change in the number partially retired is very small. This should not be an unexpected result. The number of individuals accepting window offers in any particular year is relatively small, and an individual would accept a window offer only if the individual were close to the margin of retirement, in which case he or she would probably have retired in the not too distant future anyway.

\section{Job difficulty.}

The difficulty level in any job is reduced to the median level if the job was above the median level. This applies to both the job difficulty and job stress variables. In addition, if a respondent moves from a job with above median difficulty to another original full-time job, the simulation assumes that the respondent could have continued on the same job without the loss of tenure (and wages) of moving to a new job. This implicitly assumes that the reason for the move was that the individual wanted an easier job. For those ages 58 to 67 , eliminating the effects of excess difficulty of work or stress on the job would increase the percent not retired from 1 to 1.5 percentage points. A bit more than half of the change comes from a reduction in the number of those who are partially retired.

cash benefits, 109 listed extra pension benefits, 84 listed additional years of service, 20 listed full or permanent health benefits, and 11 listed partial or temporary health benefits. In 2000, the corresponding numbers were 107 for cash bonus, 70 for improved pension benefits, 12 for temporary cash benefit, 23 for additional years of service, 14 for permanent medical insurance, and 13 for temporary medical insurance. Thus, in 1992 health benefits were only 6 percent of the total, and in 2000 they were only 11 percent. 


\section{Accommodation.}

If an individual left a job because he was not accommodated, this simulation assumes that he could have continued in the job. Implicitly, this assumes that the accommodation would be made to allow the worker to stay in the job rather than forcing the worker to move to another job, at lower wages, in order to be accommodated. The overall effects of this variable on retirements are miniscule. Nor does it appear that measures of job accommodation affect retirement prospects even if the sample is restricted just to those who suffer a health limitation.

\section{Conclusions.}

Minimum hours constraints, that is the requirements on many jobs that an individual work full time or not at all, are the major firm-side factor affecting the course of retirements. Perceived discrimination also has an effect on retirement outcomes, but its effect is much smaller. The same is true for the effects of indicators of job difficulty or stress. A reductions in the frequency of layoffs, a reduction in the frequency that window plans are offered, and increased availability of accommodations to those who report work limitations would have little effect on the overall distribution of retirement outcomes.

Should minimum hours constraints be abolished, among the population ages 62 to 69 that has a long term commitment to the labor market, the percentage completely retired will decline by 10 to 15 percentage points depending on age. The fraction in this age group working in partial retirement jobs will increase by roughly twenty percentage points. Were minimum hours constraints abolished, more than twice as many people would enter partial retirement as would leave full time work, so that total full-time equivalent (FTE) employment would increase were 
minimum hours constraints eliminated. But the change in FTE employment is much smaller than the increase in partial retirement employment.

When firms decide whether to relax minimum hours constraints, they will consider not just the very modest effect on FTE employment from relaxing these constraints. They will also consider how minimum hours constraints contribute to productivity and reduce costs. Fixed costs of employment to the firm, the role of interdependence in production and many other factors have encouraged firms to adopt minimum hours constraints in the first place. Moreover, although our simulations have assumed that constraints on partial retirement from current pension rules are eliminated, health insurance and other benefits made available on a per employee, rather than per hour basis, increase costs when firms provide a partial retirement option.

With regard to other human resource policies, it does not appear that employer efforts to change working conditions, so as to ease the burden of employment on older workers, are likely to have major effects on total FTE employment.

Our findings also suggest that if firms relaxed minimum hours constraints, this would have conflicting effects on the flow of funds from Social Security. Relaxing minimum hours constraints would encourage individuals to leave full-time work at younger ages to enter partial retirement. As a result, they would begin to draw down their benefits at an earlier age, increasing the flow of funds out of Social Security. However, they would remain in partial retirement jobs past the point where they currently retire, and during this period they would draw fewer benefits. The proportion of earnings subject to the earnings test will also be subject to conflicting forces. The fraction of earnings exempt from the earnings test will increase, but the fraction of earnings beyond the reaches of the earnings test will decline. Lastly, behavior would 
change under proposed reforms that would include personal accounts as part of Social Security. Should firms relax minimum hours constraints to encourage more partial retirement by older individuals, demand for early withdrawals from personal accounts would increase. This would increase the importance of terms and conditions regulating the timing of withdrawals from personal accounts. 


\section{References:}

Bound, John. 1989. "The Health and Earnings of Rejected Disability Insurance Applicants," American Economic Review, 79(3): 482-503.

Brown, Charles. 2000. "Early Retirement Windows". In O. Mitchell, P. Hammond, and A. Rappaport, editors. Forecasting Retirement Needs and Retirement Wealth. Philadelphia: University of Pennsylvania Press for The Pension Research Council: 253-273. 2002. "Early Retirement Windows". University of Michigan

Retirement Research Center Working Paper 2002-28. . 2003. "'Early Retirement Windows". University of Michigan

Retirement Research Center Working Paper 2003-64.

Chan, Sewin and Ann Huff Stevens. 2001. "Job Loss and Employment Patterns of Older Workers". Journal of Labor Economics 19(2): 484 - 521.

Costa, Dora. 1998. The Evolution of Retirement: An American Economic History 18801990. Chicago: University of Chicago Press. 1999. "Has the Trend Toward Early Retirement Reversed?" Paper presented at Joint Conference for the Retirement Research Consortium, "New Developments in Retirement Research". Washington, D.C.: May 20-21.

Even, William E. and David A. Macpherson. 2004. "Do Pensions Impede Phased Retirement?" September, Xeroxed.

Fields, Vivian and Robert Hutchens. 2002. "Regulatory Obstacles to Phased Retirement in the For-Profit Sector". Benefits Quarterly 18(3): 35-41.

Gordon, Roger H. and Alan S. Blinder. 1980. "Market Wages, Reservation Wages and Retirement Decision". Journal of Public Economics 14 (October): 277-308.

Gustman, Alan L., Olivia S. Mitchell, and Thomas L. Steinmeier. 1995. "Retirement Measures in the Health and Retirement Study". Journal of Human Resources 30, Supplement: S57 to S83.

Gustman, Alan L. and Thomas L. Steinmeier. 1983. "Minimum Hours Constraints and Retirement Behavior". Contemporary Policy Issues, a supplement to Economic Inquiry: 77-91. . 1984a. "Modeling the Retirement Process for Evaluation and Research". Monthly Labor Review (107)7: 26-33. . 1984b. "Partial Retirement and the Analysis of Retirement Behavior". Industrial and Labor Relations Review 37: 403-415. . 1986a. "A Structural Retirement Model," Econometrica 54(3):

$555-584$.

1986b. "A Disaggregated Structural Analysis of Retirement by

Race, Difficulty of Work and Health". Review of Economics and Statistics 67(3): 509-513. 2000. "Retirement Outcomes in the Health and Retirement

Study”. Social Security Bulletin, Perspectives 64(4). 2002. "Retirement Effects of Proposals by the President's

Commission to Strengthen Social Security". NBER Working Paper No. 10030. . 2004. "The Social Security Early Entitlement Age In A Structural Model of Retirement and Wealth". Journal of Public Economics.

Haider, Steven and David Loughran. 2001. "Elderly Labor Supply: Work or Play?". Working Paper, Center for Retirement Research, September. WP 2001-04. 
Hurd, Michael D. 1996. "The Effect of Labor Market Rigidities on the Labor Force Behavior of Older Workers". In David A. Wise, editor. Advances in the Economics of Aging. Chicago: University of Chicago Press: 11 - 58.

Penner, Rudolph G., Pamela Perun and C. Eugene Steuerle. 2002. "Legal and Institutional Impediments to Partial Retirement and Part-Time Work by Older Workers". http//www.urban.org/url.cfm?ID=410587.

Quinn, Joseph F. 2002. "Has the Early Retirement Trend Reversed?" Paper presented at Joint Conference for the Retirement Research Consortium, "New Developments in Retirement Research". Washington, D.C.: May 20-21. 
Table 1

The Derivation of the Sample of Long-Term Married Men

Total males in sample

Not married

Not married long term

Spouse not interviewed if married

No career employment

Ambiguity about whether jobs are social security covered

No full-time earnings in Social Security record or self report

No self-reported earnings, and social security earnings over limit

Relatively large business assets

No Pension Provider record in last job

Full-time years unavailable for spouse

Number
eliminated $\begin{gathered}\text { Number } \\ \text { remaining in } \\ \text { the sample }\end{gathered}$

5867

$939 \quad 4928$

$639 \quad 4289$

$133 \quad 4156$

$497 \quad 3659$

$49 \quad 3610$

$36 \quad 3574$

$31 \quad 3543$

$291 \quad 3252$

$865 \quad 2384$

$156 \quad 2231$ 
Table 2

The Distribution of Observed Retirements in the Sample

Age

50

51

52

53

54

55

56

57

58

59

60

61

62

63

64

65

66

67

68

69

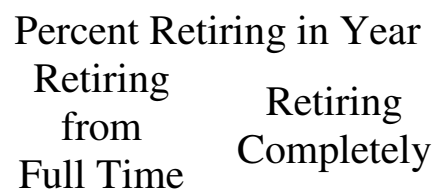

4.1

0.9

2.7

2.0

2.1

3.1

1.9

4.0

3.0

3.6

6.0

6.3

15.1

5.6

6.7

9.1

4.5

2.8

3.1

1.7
3.3

0.0

2.2

1.1

1.3

2.7

2.1

3.2

2.1

2.1

6.4

5.5

12.5

3.4

6.7

6.7

3.9

2.9

3.3

4.6
Percent Retired

$\begin{array}{ccc}\begin{array}{c}\text { Retiring } \\ \text { from }\end{array} & \begin{array}{c}\text { Completely } \\ \text { Fetired }\end{array} & \begin{array}{c}\text { Number of } \\ \text { observations }\end{array}\end{array}$

4.1

5.0

7.6

9.7

11.8

14.9

16.8

20.8

23.8

27.4

33.4

39.7

54.8

60.4

67.1

76.2

80.7

83.5

86.7

88.4

\section{3}

3.3

5.5

6.6

7.9

10.6

12.7

15.9

18.0

20.1

26.4

31.9

44.4

47.9

54.6

61.3

65.2

68.1

71.4

76.0
243

361

510

621

712

801

907

990

1064

1132

1121

1043

986

909

843

744

658

565

472

379 
Table 3

Estimation of Parameters of the Utility Function with Measures of Job Conditions Included

\begin{tabular}{clcc} 
Symbol & \multicolumn{1}{c}{ Description } & $\begin{array}{c}\text { Coefficient } \\
\text { Value }\end{array}$ & $\begin{array}{c}\mathrm{t}- \\
\text { statistic }\end{array}$ \\
& & & \\
$\alpha$ & Consumption & -0.42 & 4.53 \\
$\beta_{0}$ & Constant & -10.28 & 157.56 \\
$\beta_{1}$ & Age & 0.12 & 4.62 \\
$\beta_{2}$ & Health & 3.34 & 4.08 \\
$\beta_{3}$ & Vintage & 0.03 & 0.36 \\
$\beta_{4}$ & Job Difficulty & -0.13 & 1.34 \\
$\beta_{5}$ & Job Stress & 0.18 & 1.24 \\
$\beta_{6}$ & Age Discrimination & 0.33 & 1.83 \\
$\beta_{7}$ & No Accommodation & -0.97 & 0.61 \\
$\delta_{0}$ & Constant & -2.89 & 5.40 \\
$\delta_{1}$ & Age & 0.38 & 2.84 \\
$\sigma_{\varepsilon}$ & Standard Deviation of $\varepsilon$ & 5.50 & 12.97 \\
\multicolumn{4}{c}{ Number obs. } \\
q: & 2231 &
\end{tabular}

Distribution of Time Preference Rates

$\begin{array}{cc}0.00-0.05 & 27.3 \% \\ 0.05-0.10 & 23.9 \\ 0.10-0.15 & 8.5 \\ 0.15-0.20 & 3.7 \\ 0.20-0.25 & 2.0 \\ >0.25 & 34.6\end{array}$


Table 4

Simulated Retirements Based on Estimates in Complete Model From Table 3

\begin{tabular}{|c|c|c|c|c|}
\hline & \multicolumn{2}{|c|}{ Percent Retiring in Year } & \multicolumn{2}{|c|}{ Percent Retired } \\
\hline & $\begin{array}{l}\text { Retiring } \\
\text { from } \\
\text { Full Time }\end{array}$ & $\begin{array}{c}\text { Retiring } \\
\text { Completely }\end{array}$ & $\begin{array}{l}\text { Retiring } \\
\text { from } \\
\text { Full Time }\end{array}$ & $\begin{array}{c}\text { Completely } \\
\text { Retired }\end{array}$ \\
\hline Age & & & & \\
\hline 50 & 1.3 & 0.8 & 4.6 & 2.8 \\
\hline 51 & 1.4 & 1.0 & 6.0 & 3.8 \\
\hline 52 & 1.7 & 1.2 & 7.7 & 5.0 \\
\hline 53 & 2.2 & 1.7 & 9.9 & 6.7 \\
\hline 54 & 2.9 & 2.1 & 12.8 & 8.8 \\
\hline 55 & 3.1 & 2.4 & 15.9 & 11.2 \\
\hline 56 & 3.7 & 2.8 & 19.6 & 14.0 \\
\hline 57 & 4.3 & 3.4 & 23.8 & 17.4 \\
\hline 58 & 4.6 & 3.7 & 28.4 & 21.1 \\
\hline 59 & 6.7 & 5.4 & 35.1 & 26.5 \\
\hline 60 & 5.6 & 4.6 & 40.8 & 31.1 \\
\hline 61 & 12.8 & 9.2 & 53.6 & 40.3 \\
\hline 62 & 4.8 & 4.0 & 58.4 & 44.3 \\
\hline 63 & 5.2 & 4.6 & 63.6 & 48.9 \\
\hline 64 & 8.6 & 7.8 & 72.2 & 56.7 \\
\hline 65 & 5.2 & 5.2 & 77.3 & 61.9 \\
\hline 66 & 4.3 & 4.5 & 81.7 & 66.4 \\
\hline 67 & 4.2 & 4.6 & 85.8 & 71.0 \\
\hline 68 & 3.9 & 6.1 & 89.7 & 77.0 \\
\hline 69 & 1.3 & 0.8 & 88.4 & 76.0 \\
\hline
\end{tabular}

Percent of simulated retirements into partial retirement: 30.0 
Table 5

Percentages of Retirement from Full-Time Jobs for Married Males in 1992

\begin{tabular}{|c|c|c|c|c|}
\hline \multirow[b]{2}{*}{ Age } & \multicolumn{2}{|c|}{$\begin{array}{l}\text { Self-Reported } \\
\text { Retirement }\end{array}$} & \multicolumn{2}{|c|}{$\begin{array}{l}\text { Retirement Definec } \\
\text { by Hours }\end{array}$} \\
\hline & $\begin{array}{l}\text { White } \\
\text { Collar }\end{array}$ & $\begin{array}{l}\text { Blue } \\
\text { Collar }\end{array}$ & $\begin{array}{l}\text { White } \\
\text { Collar }\end{array}$ & $\begin{array}{l}\text { Blue } \\
\text { Collar }\end{array}$ \\
\hline 55 & $19 \%$ & $21 \%$ & $26 \%$ & $25 \%$ \\
\hline 56 & 25 & 18 & 28 & 28 \\
\hline 57 & 17 & 22 & 23 & 27 \\
\hline 58 & 29 & 28 & 31 & 35 \\
\hline 59 & 21 & 28 & 24 & 35 \\
\hline 60 & 33 & 32 & 39 & 38 \\
\hline 61 & 32 & 41 & 34 & 42 \\
\hline 62 & 40 & 58 & 41 & 61 \\
\hline 63 & 68 & 69 & 67 & 60 \\
\hline 64 & 50 & 74 & 45 & 73 \\
\hline 65 & 73 & 83 & 62 & 83 \\
\hline \multirow[t]{2}{*}{$\begin{array}{l}\text { Weighted } \\
\text { Average }\end{array}$} & $31.8 \%$ & $37.2 \%$ & $34.3 \%$ & $41.0 \%$ \\
\hline & \multicolumn{4}{|c|}{$\begin{array}{l}\text { Among Respondents in Good Health } \\
\text { Who Have Never Received SSDI }\end{array}$} \\
\hline 55 & $16 \%$ & $9 \%$ & $23 \%$ & $14 \%$ \\
\hline 56 & 21 & 10 & 25 & 16 \\
\hline 57 & 12 & 13 & 18 & 18 \\
\hline 58 & 25 & 19 & 26 & 24 \\
\hline 59 & 21 & 19 & 21 & 26 \\
\hline 60 & 31 & 21 & 34 & 22 \\
\hline 61 & 28 & 34 & 30 & 35 \\
\hline 62 & 40 & 48 & 40 & 51 \\
\hline 63 & 65 & 60 & 63 & 51 \\
\hline 64 & 50 & 67 & 44 & 68 \\
\hline 65 & 69 & 76 & 60 & 75 \\
\hline $\begin{array}{l}\text { Weighted } \\
\text { Average }\end{array}$ & $28.9 \%$ & $26.3 \%$ & $30.7 \%$ & $29.6 \%$ \\
\hline
\end{tabular}


Table 6

Observed Retirements for Married Men

Whose Employers Did Not Accommodate Health Problems

\begin{tabular}{|c|c|c|c|}
\hline & \multicolumn{2}{|c|}{ Percent Retired } & \multirow[b]{2}{*}{$\begin{array}{l}\text { Number of } \\
\text { observations }\end{array}$} \\
\hline & $\begin{array}{l}\text { Retiring } \\
\text { from } \\
\text { Full Time }\end{array}$ & $\begin{array}{l}\text { Completely } \\
\text { Retired }\end{array}$ & \\
\hline 55 & 14.3 & 9.5 & 42 \\
\hline 56 & 14.8 & 14.8 & 54 \\
\hline 57 & 10.7 & 10.7 & 56 \\
\hline 58 & 13.0 & 13.0 & 54 \\
\hline 59 & 18.5 & 16.7 & 54 \\
\hline 60 & 33.3 & 29.4 & 51 \\
\hline 61 & 36.6 & 34.1 & 41 \\
\hline 62 & 68.6 & 65.7 & 35 \\
\hline 63 & 71.0 & 64.5 & 31 \\
\hline 64 & 71.4 & 61.9 & 21 \\
\hline 65 & 66.7 & 60.0 & 15 \\
\hline
\end{tabular}


Table 7

Alternative Specifications

\begin{tabular}{|c|c|c|c|c|}
\hline \multirow[t]{2}{*}{ Symbol } & \multirow[t]{2}{*}{ Description } & \multicolumn{3}{|c|}{$\begin{array}{l}\text { Coefficient Values } \\
\text { (absolute t-statistics) }\end{array}$} \\
\hline & & (1) & (2) & (3) \\
\hline$\alpha$ & Consumption & $\begin{array}{l}-0.42 \\
(4.53)\end{array}$ & $\begin{array}{l}-0.44 \\
(4.76)\end{array}$ & $\begin{array}{l}-0.42 \\
(5.20)\end{array}$ \\
\hline$\beta_{0}$ & Constant & $\begin{array}{c}-10.28 \\
(157.56)\end{array}$ & $\begin{array}{c}-10.30 \\
(150.63)\end{array}$ & $\begin{array}{c}-10.30 \\
(178.64)\end{array}$ \\
\hline$\beta_{1}$ & Age & $\begin{array}{c}0.12 \\
(4.62)\end{array}$ & $\begin{array}{c}0.12 \\
(4.76)\end{array}$ & $\begin{array}{c}0.12 \\
(4.69)\end{array}$ \\
\hline$\beta_{2}$ & Health & $\begin{array}{c}3.34 \\
(4.08)\end{array}$ & $\begin{array}{c}3.31 \\
(4.37)\end{array}$ & $\begin{array}{c}3.45 \\
(4.43)\end{array}$ \\
\hline$\beta_{3}$ & Vintage & $\begin{array}{c}0.03 \\
(0.36)\end{array}$ & $\begin{array}{c}0.03 \\
(0.35)\end{array}$ & $\begin{array}{c}0.03 \\
(0.35)\end{array}$ \\
\hline$\beta_{4}$ & Job Difficulty & $\begin{array}{l}-0.13 \\
(1.34)\end{array}$ & $\begin{array}{l}-0.12 \\
(1.27)\end{array}$ & \\
\hline$\beta_{5}$ & Job Stress & $\begin{array}{c}0.18 \\
(1.24)\end{array}$ & $\begin{array}{c}0.15 \\
(1.01)\end{array}$ & \\
\hline$\beta_{6}$ & Age Discrimination & $\begin{array}{c}0.33 \\
(1.83)\end{array}$ & $\begin{array}{c}0.38 \\
(2.03)\end{array}$ & $\begin{array}{c}0.37 \\
(1.96)\end{array}$ \\
\hline$\beta_{7}$ & No Accommodation & $\begin{array}{l}-0.97 \\
(0.61)\end{array}$ & & \\
\hline$\delta_{0}$ & Constant & $\begin{array}{l}-2.89 \\
(5.40)\end{array}$ & $\begin{array}{l}-2.97 \\
(5.69)\end{array}$ & $\begin{array}{l}-3.00 \\
(5.69)\end{array}$ \\
\hline$\delta_{1}$ & Age & $\begin{array}{l}0.38 \\
(2.84)\end{array}$ & $\begin{array}{c}0.40 \\
(2.73)\end{array}$ & $\begin{array}{c}0.49 \\
(3.05)\end{array}$ \\
\hline$\sigma_{\varepsilon}$ & Standard Deviation of $\varepsilon$ & $\begin{array}{c}5.50 \\
(12.97)\end{array}$ & $\begin{array}{c}5.44 \\
(12.45)\end{array}$ & $\begin{array}{c}5.43 \\
(12.16)\end{array}$ \\
\hline q Statistic & & 86.82 & 80.54 & 71.77 \\
\hline
\end{tabular}


Table 8

Results of Retirement Simulations from Relaxing the Indicated Factor

(Numbers reported are in percentages)

Age

Full Sample Baseline percent completely retired percent partially retired percent not retired

No Hours Limits percent completely retired percent partially retired percent not retired

No Age Discrimination percent completely retired percent partially retired percent not retired

No Layoffs

percent completely retired percent partially retired percent not retired

No Windows

percent completely retired percent partially retired percent not retired

No Job Difficulty or Stress percent completely retired percent partially retired percent not retired

Accommodation if Necessary percent completely retired percent partially retired percent not retired $\begin{array}{llllll}55 & 58 & 60 & 62 & 65 & 67\end{array}$

$\begin{array}{rrrrrrr}8.8 & 17.5 & 26.5 & 40.2 & 56.5 & 66.1 & 76.7 \\ 4.1 & 6.4 & 8.7 & 13.5 & 15.7 & 15.5 & 13.0 \\ 87.1 & 76.1 & 64.8 & 46.3 & 27.8 & 18.4 & 10.3\end{array}$

$\begin{array}{lll}6.4 & 12.8 & 19.6\end{array}$

29.7

$\begin{array}{lll}11.9 & 18.6 & 24.8\end{array}$

$81.7 \quad 68.6 \quad 55.6$

$\begin{array}{rrrrrrr}8.6 & 16.9 & 25.8 & 39.7 & 56.3 & 66.0 & 76.7 \\ 3.8 & 6.0 & 8.1 & 12.7 & 15.2 & 15.1 & 12.7 \\ 87.6 & 77.1 & 66.1 & 47.6 & 28.5 & 18.9 & 10.6\end{array}$

$\begin{array}{rrrrrrrr}8.8 & 17.7 & 26.3 & 40.1 & 56.6 & 66.2 & 76.9 & \\ 4.1 & 6.2 & 8.6 & 13.3 & 15.6 & 15.5 & 12.9 & 29.8 \\ 87.1 & 76.1 & 65.1 & 46.6 & 27.8 & 18.3 & 10.2 & \end{array}$

$\begin{array}{rrrrrrr}8.7 & 17.0 & 26.2 & 39.9 & 56.5 & 66.2 & 76.8 \\ 4.0 & 6.3 & 8.5 & 13.4 & 15.8 & 15.5 & 12.9 \\ 87.3 & 76.7 & 65.3 & 46.7 & 27.7 & 18.3 & 10.3\end{array}$

29.9

$\begin{array}{lllllll}8.5 & 16.9 & 25.8 & 39.6 & 56.1 & 65.8 & 76.5\end{array}$

$\begin{array}{rrrrrrr}3.9 & 6.0 & 8.1 & 12.6 & 15.0 & 14.9 & 12.7\end{array}$

$\begin{array}{lllllll}87.6 & 77.1 & 66.1 & 47.8 & 28.9 & 19.3 & 10.8\end{array}$

28.6

$\begin{array}{lllllll}8.8 & 17.4 & 26.5 & 40.2 & 56.5 & 66.1 & 76.7\end{array}$

$\begin{array}{rrrrrrr}4.1 & 6.5 & 8.6 & 13.4 & 15.7 & 15.5 & 13.0\end{array}$

$\begin{array}{lllllll}87.1 & 76.1 & 64.9 & 46.4 & 27.8 & 18.4 & 10.3\end{array}$

29.9

66.9

28.9

29.8

Percent into partial retirement

9


Table 9

Results of Retirement Simulations from Relaxing the Indicated Factor Relative to Baseline (Numbers reported are in percentages)

Age percent completely retired percent partially retired percent not retired

Difference: No Age

Discrimination percent completely retired percent partially retired percent not retired

Differences: No Layoffs percent completely retired percent partially retired percent not retired

Differences: No Windows percent completely retired percent partially retired percent not retired

Differences: No Job Difficulty or Stress percent completely retired percent partially retired percent not retired

Differences: Accommodation if Necessary percent completely retired percent partially retired percent not retired

$\begin{array}{llllll}55 & 58 & 60 & 62 & 65 & 67\end{array}$

67

69

$\begin{array}{rrrrrrr}-2.4 & -4.7 & -6.9 & -10.5 & -14.1 & -15.3 & -13.8 \\ 7.8 & 12.2 & 16.1 & 20 & 22.1 & 21.2 & 16.9 \\ -5.4 & -7.5 & -9.2 & -9.5 & -8 & -5.9 & -3.1\end{array}$

$\begin{array}{rrrrrrrr}-0.2 & -0.6 & -0.7 & -0.5 & -0.2 & -0.1 & 0.0 & \\ -0.3 & -0.4 & -0.6 & -0.8 & -0.5 & -0.4 & -0.3 & -1 \\ 0.5 & 1.0 & 1.3 & 1.3 & 0.7 & 0.5 & 0.3 & \end{array}$

$\begin{array}{rrrrrrr}0.0 & 0.2 & -0.2 & -0.1 & 0.1 & 0.1 & 0.2 \\ 0.0 & -0.2 & -0.1 & -0.2 & -0.1 & 0.0 & -0.1 \\ 0.0 & 0.0 & 0.3 & 0.3 & 0.0 & -0.1 & -0.1\end{array}$

$\begin{array}{lllllll}-0.1 & -0.5 & -0.3 & -0.3 & 0.0 & 0.1 & 0.1\end{array}$ $\begin{array}{lllllll}-0.1 & -0.1 & -0.2 & -0.1 & 0.1 & 0.0 & -0.1\end{array}$ 0.0

$\begin{array}{lllllll}0.2 & 0.6 & 0.5 & 0.4 & -0.1 & -0.1 & 0.0\end{array}$

$\begin{array}{rrrrrrrr}-0.3 & -0.6 & -0.7 & -0.6 & -0.4 & -0.3 & -0.2 & \\ -0.2 & -0.4 & -0.6 & -0.9 & -0.7 & -0.6 & -0.3 & -1.3 \\ 0.5 & 1.0 & 1.3 & 1.5 & 1.1 & 0.9 & 0.5 & \end{array}$

$\begin{array}{rrrrrrrr}0.0 & -0.1 & 0.0 & 0.0 & 0.0 & 0.0 & 0.0 & \\ 0.0 & 0.1 & -0.1 & -0.1 & 0.0 & 0.0 & 0.0 & 0.0 \\ 0.0 & 0.0 & 0.1 & 0.1 & 0.0 & 0.0 & 0.0 & \end{array}$




\section{Appendix 1. Construction of Variables.}

Retirement variable.

Retirement outcomes fall into three categories. Full time workers are employed more than 30 hours per week and more than 1560 hours per year. Those who are partially retired are working more than 100 hours per year but less than 25 hours per week. Individuals who fall between full-time and partial retirement, or between partial retirement and complete retirement are classified on the basis of self reports.

\section{Job characteristics.}

We use questions from items F82 and F83 and their counterparts on later surveys.

Because some of the questions in the earlier surveys were dropped in later surveys, we used only questions which are common across surveys and which arguably reflect on the difficulty of a job.

In the end, there are six questions:

My job requires a lot of physical effort.

My job requires lifting heavy loads.

My job requires stooping, kneeling, or crouching.

My job requires intense concentration or attention.

My job requires me to do more difficult things than it used to.

My job involves a lot of stress.

All of these are answered on a scale of 1 to 4 , with 1 being strong agreement and 4 being strong disagreement.

The responses to the questions are put through a factor analysis. The factor loadings are as follows:

$\begin{array}{lcccccc}\text { Job Involves } & 1 & 2 & 3 & 4 & 5 & 6 \\ \text { Physical Effort } & 0.57 & 0.02 & 0.02 & -0.03 & -0.68 & -0.45 \\ \text { Heavy Loads } & 0.58 & 0.00 & -0.05 & -0.07 & -0.04 & 0.81 \\ \text { Stooping, Kneeling, Crouching } & 0.57 & -0.00 & -0.04 & 0.05 & 0.73 & -0.37 \\ \text { Intense Concentration } & 0.04 & 0.51 & 0.79 & 0.33 & 0.02 & 0.05 \\ \text { More Difficult over Time } & -0.01 & 0.57 & -0.60 & 0.55 & -0.04 & -0.02\end{array}$


$\begin{array}{lllllll}\text { Involves a Lot of Stress } & -0.04 & 0.64 & -0.10 & -0.76 & 0.05 & -0.04\end{array}$

Note that the first vector has loadings of approximately equal weights for the first three variables, and the second vector has loadings of approximately equal weights for the last three variables. Together these two vectors explain nearly two-thirds of the variance.

Given these results, we create two new variables, which we call job difficulty and job stress. The first simply sums the first three variables and the second sums the last three variables. The sums of the raw data run from 3 to 12 , but for the analysis they are rescaled and reversed to run from 0 to 9 , so that 9 indicates strong agreement on all three questions. The median value of the job difficulty variable is 3, and the median value of job stress is 6 .

The survey also contains three questions in item F85 related to age discrimination. These three questions are repeated in later surveys as well. They are:

In decisions about promotion, my employer gives younger people preference over older people.

My co-workers make older workers feel that they ought to retire before age 65 .

My employer would let older workers move to a less demanding job with less pay if they wanted to.

The responses to these questions are also put through a factor analysis, with the following loadings on the factors:

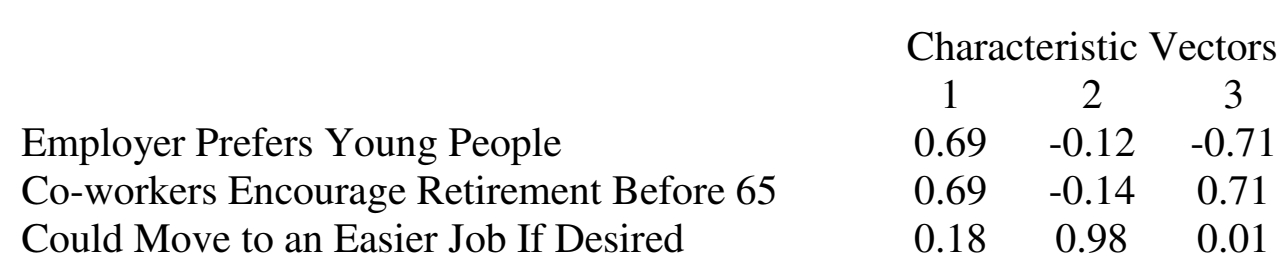

The first two variables are loaded onto the first vector with almost equal weight, and the second vector is virtually identical with the third variable. The first vector accounts for half the variance, and the first two vectors account for 82 percent. 
Given these results, we create a single variable for age discrimination by adding the first two variables. Since these variables have values from 1 to 4 , with 1 being associated with the most discrimination, the sum of the raw data ranges from 2 to 8 . The variable used in the analysis is rescaled and reversed to form a variable running from 0 to 6 , with 6 corresponding to the most discrimination. The median value of the age discrimination variable is 2 . The third variable, which measures employer flexibility, is closely related to another variable we will analyze, which is whether the employer will permit the worker to reduce work to half time on the job. As such, we did not enter it into the utility function directly.

Since these questions are asked each survey, there is the possibility that there may be more than one answer for a particular job. In the case of the job held in 1992, we use the last set of answers for that job on the premise that those values are probably most relevant to the decision as to whether to retire from that job. If the respondent worked on jobs subsequent to the job held in 1992, we also use the last observed responses to these questions for those jobs, again on the premise that those responses were the most relevant to the work/retirement decision.

A problem occurs in the cases where these variables have values that are missing. Relatively few individuals refused to answer them, but they were not asked of individuals who are not working. This is particularly a problem if the respondent was retired in the first survey and stayed retired. Simply dropping these individuals is tantamount to dropping observations based on the value of retirement, the dependent variable. Rather than dropping, we impute the variables based on the distributions that we do observe.

The imputation for the job difficulty variable is based on occupation. The average value of job difficulty for each industry is given in Table A1. These values are computed for males with current jobs in 1992. In a regression where the observations are individuals and the 
dependent value is the job difficulty variable, the set of 17 occupation dummy variables accounts for 30 percent of the variance. The means for industries are much closer, and the regression using industry dummies accounts for only 14 percent of the variance. Moreover, the industry variables add almost nothing to the explanation provided by the occupation dummy variables. In this case, for a missing job difficulty variable, we take the distribution of the observed job difficulty variables in the particular occupation, and take a random draw from that distribution. Since occupation was asked in sections G and H (last and longest job) of the 1992 survey, it is available even for individuals who had retired prior to the first wave of the HRS. Note that this strategy has some potential for errors in variables causing the estimates of the effects to be biased toward zero, but whatever the bias, it is probably not too great, given that only 12 percent of the sample reported themselves as completely retired in the first wave of the survey (Gustman and Steinmeier, 2000).

The approach of using occupation and/or industry as instruments is less successful for the job stress and age discrimination variables. The combination of industry and occupation dummies together are able to explain only 6 percent of the variation in the job stress variable and only 3 percent of the age discrimination variable. These are so low that the imputations were based on the observed distributions of the job stress and age discrimination variables for the entire sample.

In some cases, the HRS indicates that the individual left the 1992 job and took another job, but does not provide enough information to calculate the job characteristics of that job. In these cases, the characteristics of the new job are imputed by taking a random draw from the distribution of characteristics in new jobs, given the characteristics in the original jobs that are observed for individuals for whom the characteristics of both jobs are observed. 
Another variable that is entered into the utility function is a variable indicating whether, for a respondent that reported a condition that limited the amount of work they could do, the respondent's employer had made no accommodations so that the respondent could continue to work. These questions are of the form "does your employer currently do anything special to make it easier for you to stay at work?" (question J109) or "At the time your health started to limit your ability to work, did your employer do anything special to help you out so that you could stay at work?" (question J38 in 1992) These types of questions follow the self reported health questions as to whether the respondent had any impairment or health problem that limits the kind or amount of paid work or work around the house that they can do. If the respondent had a health problem (using the same definition we have used in the past) and if the response to the accommodation question is "no" or "left job immediately," the "no accommodation" variable is set equal to 1 . Otherwise, it is set equal to 0 . The 0 responses cover the answers "yes", "no accommodation needed", and "self employed" responses. Note that the "no accommodation needed" response was added in later surveys. We are particularly interested in whether there was accommodation in the 1992 job or, if the individual was not working full-time in 1992, in the previous full-time job. 
Table A1.

Mean Job Difficulty by Occupation
Occupation Number

Description

$\begin{array}{ll}1 & \text { Managerial specialty operation } \\ 2 & \text { Professional specialty operation, technical support } \\ 3 & \text { Sales } \\ 4 & \text { Clerical, administrative support } \\ 5 & \text { Service: private household, cleaning and building } \\ 6 & \text { Service: protection } \\ 7 & \text { Service: food preparation } \\ 8 & \text { Health services } \\ 9 & \text { Personal services } \\ 10 & \text { Farming, forestry, fishing } \\ 11 & \text { Mechanics and repair } \\ 12 & \text { Construction trade and extractors } \\ 13 & \text { Precision production } \\ 14 & \text { Operators: machine } \\ 15 & \text { Operators: transport, etc } \\ 16 & \text { Operators: handlers, etc } \\ 17 & \text { Member of Armed Forces }\end{array}$

$\begin{array}{lc}\text { Mean Job } & \text { Number of } \\ \text { Difficulty } & \text { Observations }\end{array}$

$\begin{array}{lc}1.8 & 766 \\ 1.4 & 575 \\ 2.3 & 440 \\ 2.8 & 206 \\ 1.3 & 3 \\ 2.1 & 111 \\ 4.9 & 37 \\ 4.9 & 9 \\ 4.4 & 184 \\ 5.4 & 225 \\ 4.8 & 292 \\ 6.0 & 279 \\ 3.9 & 211 \\ 4.4 & 281 \\ 4.2 & 372 \\ 5.6 & 159 \\ 0.8 & 6\end{array}$

